\title{
Is There Now a Role for Economic Instruments in New Zealand's Domestic Climate Change Policy?
}

\section{Murray Ward}

\section{Introduction}

In late December 2005, the reconstituted Labour-led government announced that a carbon charge would not be introduced in 2007. Indeed, it now appears that there will be no broad-based economic instrument to mitigate climate change before 2012. This story made the world's climate change press. A carbon charge has been on New Zealand's policy agenda since the mid-1990s, and until very recently had been supported by both centre-right and centre-left governments. It was the centrepiece of the climate change policy announced by the Labourled government in 2002 when it ratified the Kyoto Protocol. So why the abrupt change of policy?

It is likely that politics played a key role. The government had not enacted legislation in its previous term to give effect to the planned carbon tax. As a result of the general election in September 2005, it was questionable whether the new minority government could muster the numbers to pass such a bill. During the election campaign four parties, including two that would become support partners for Labour in October 2005, spoke out strongly against the carbon tax - and Kyoto. Moreover, the 'carbon tax' had become demonised over recent years by a range of business groups.

This brief article does not delve into the politics of this situation. Rather, it looks at the role in the decision to abandon the carbon tax of an interdepartmental Policy Review commenced in mid-2005, and delivered to the new Cabinet in early December. The Review was started because of a realisation that New Zealand is no longer on track to be a net seller in the Kyoto market. For years it had been thought, based on projections, that New Zealand's considerable growth in emissions (along with growth in its economy) would still be more than offset by the sink credits generated from its afforestation efforts in the 1990s. The news had changed in early 2005 when officials did their annual inventory and projection sums based on the actual planting rates and using the recently agreed new international rules for accounting. Now there is a projected deficit, not surplus.

\section{The Policy Review and officials' advice to the Cabinet}

An assessment of the Cabinet paper presented to the new government on the outcomes of the Policy Review reveals key policy issues and raises many questions. ${ }^{1}$ The advice represents, to a significant degree, a full rebuttal of the use of economic instruments that were the core of the 2002 policy package to address climate change issues. This has been surprising to many observers, as they had expected an outcome of the Review to be a ramping up of policy efforts, not a wholesale deconstruction.

Key features of the advice and recommendations include:

- With respect to the carbon charge - referred to as the 'carbon tax model', which incorporates the negotiated greenhouse agreements (NGAs) element - the Cabinet paper asked the Cabinet to agree that the carbon tax would not start at the previously announced date of 1 April 2007, and also to agree on one of four options. Three of these entailed, to varying degrees, not introducing a carbon tax or any other broad-based greenhouse gas tax; the fourth was to defer a decision until early March 2006 following further consideration of the outcomes of the Review.

- In keeping with these agree recommendations, the Cabinet was asked to note the Review Report's conclusion that emission reductions cannot be achieved at the lowest cost if NGAs and the exemption for livestock methane and nitrous oxide from a greenhouse gas tax were extended well beyond 2012, and that the carbon tax and associated NGAs are unlikely to be

The report of the Policy Review and the Cabinet paper and associated Cabinet minute can be found on the New Zealand government's climate change website at http://www.climaechange.govt.nz/. 
sustainable over the medium term and would need to be replaced by some other policy package.

- On agricultural emissions (methane and nitrous oxide from livestock), the paper asked the Cabinet to confirm that these emissions would remain exempt from any broad based greenhouse gas tax until 2012.

- On the Projects to Reduce Emissions (PRE) programme, the Cabinet was asked to agree that the third round would not proceed.

- On emissions trading, the Cabinet was to note that one of the key findings of the Policy Review was that the government should not develop a New Zealand emissions trading scheme to apply in the period 20082012, but should consider it for post- 2012 .

Of the agree options provided on the carbon tax, the Cabinet decided not to introduce the carbon tax model or any other broad-based greenhouse gas tax before the end of the Kyoto Protocol first commitment period (KP CP1) - while noting that this did not preclude a more narrowlybased tax on large emitters if this was deemed appropriate.

Against this, with regard to the PRE programme, the Cabinet rejected the advice received and agreed that the third round would proceed. In keeping with this, it directed officials in their March 2006 report back to provide advice on how to achieve greater assurance that the emission reductions resulting from projects will be greater than the emission units given away to project owners.

What was the thinking that underlay this sweeping rejection of the 2002 policy package on climate change? A perhaps cynical and boiled-down judgement of the Policy Review and the related Cabinet paper might be that it ended up in something of a 'policy no man's land'. The Review seems to seek efficiency through broadly applied price-based measures. Exemptions from these 'sticks' are seen as distortionary and inefficient. But then there are competitiveness issues, and the practicalities of applying stick measures to the agriculture sector. Linking to the international carbon price seems scary. Other possible economic instrument tools (like projects schemes) are really just subsidies, so they are bad. Smart revenue recycling? Not even contemplated. And emissions trading is just all too complex. So what is the answer? Give up on economic instruments and just have the taxpayer buy New Zealand's way out of KP CP1. And adjust the environmental goals so this doesn't look too bad. Oh, and better not think too hard about CP2 ... for now at least.
This may be overly harsh. But where has the Policy Review got to, or pointed to, that is significantly different than this? One matter is clear: the Review will not have added any certainty in this important area. Yet policy certainty is a key objective of business, and a valuable commodity in other respects.

\section{The 2002 policy environment and policy package}

A more analytical and objective assessment of the Policy Review reveals some key points. The first is how little the 2002 policy and its underlying objectives seem to be now remembered and understood. The overarching policy environment in 2002:

- took the economic and social risks of climate change to New Zealand and the immediate Pacific region seriously, and set domestic policy within a risk management strategy that involved New Zealand actively seeking greater engagement of the world's large emitters. This strategy recognised the importance of this country maintaining credibility in order to be effective in this effort;

- cared about the efficiency of New Zealand's response and worried about costs imposed on the economy and taxpayers as a result of inefficient investments with long-term emissions consequences;

- assumed that it was more likely than not that quantitative constraints on countries' greenhouse emissions would become more stringent in the future; and

- considered that New Zealand's international credibility would be seriously affected if it withdrew from international action to address the risks of climate change, and that this effect on international credibility could have severe economic and political implications across New Zealand's wide range of engagements with the outside world.

Put simply, the prime objective of using economic instruments and putting them at the core of the 2002 policy was to place an opportunity cost linked to the international price of carbon on all emissions in the energy sector. This was to be done through an innovative mix of policy tools. The use of economic instruments to help manage $\mathrm{CO}_{2}$ emissions reflected the desire of the government to tilt the economic playing field towards climate-friendly actions, both on the supply side (e.g. new 
investments in electricity generation more likely to be renewables or higher efficiency/less carbon-intensive thermal) and the demand side (e.g. improved economics of energy efficiency and fuel switching measures).

A policy tool, or package of tools, was needed to do this. The 2002 package, arrived at after many years of analysis and rounds of stakeholder consideration, ${ }^{2}$ chose a carbon charge at the estimated international price as the core economic policy tool. This charge was primarily on $\mathrm{CO}_{2}$ emissions in the energy sector. All revenue from climate change policies was to be redistributed back into the economy, e.g. through the tax system and climate change projects/programmes.

Recognising the potential 'lose-lose' situation ${ }^{3}$ that may be faced by many of New Zealand's leading industries that face significant international competitiveness risks, the policy included a negotiated greenhouse agreements exemption programme. A set of Kyoto-like flexibilities were included to ensure these firms would also face the opportunity cost of the international carbon price.

Agricultural sector non- $\mathrm{CO}_{2}$ emissions and some other non- $\mathrm{CO}_{2}$ emissions were not covered by the charge. Instead, government sought a funding partnership for research to find opportunities to reduce emissions. This recognised the different nature and number of opportunities and decision makers in these sectors.

To address the potential of inefficiencies in sectors not covered by the charge, and even those covered by the charge where market failures may exist, a projects-based scheme was proposed that would see emitters faced with the opportunity cost of the international carbon price. But this could be done without imposing a cost.

The final part of the package was that it could be converted to more of an emissions trading model relatively seamlessly if the international conditions became appropriate. In 2002 it was uncertain if or when this might be the case. (By 2005 it had become clear that most countries with Kyoto targets see emissions trading as their core marketbased policy tool, not a carbon charge.)

2 In contrast, many groups complained about the Policy Review's 'closed shop', non-transparent process.

3 Emissions displaced outside the Kyoto cap that covers New Zealand's means an absolute increase of emission to the atmosphere. The second 'lose' is the reduction of economic activity in New Zealand.

\section{New thinking}

The hinge pin of the Review's new tack might be seen in a discussion on whether it is important for New Zealand to be linked to the international price of carbon. This issue is taken up in the Review following a section discussing possible alternative policy options. After making the point that the 2002 policy is based on a central principle that the carbon price should reflect the international price, it goes on to say:

Most of the options discussed earlier in this section involve a decoupling of the domestic price from the international price in the short term (to 2012), and some options would continue this into the medium term and perhaps longer. Does this matter?

In short, this section concedes that in the event that New Zealand faces a quantitative commitment, as in Kyoto's CP1, the taxpayer will bear the cost of any additional emissions that may occur because the international price is not reflected: 'Taxpayers would pay more and emitters would pay less.' But it says this fiscal outcome needs to be 'weighed against any adverse effects from a reduction in international competitiveness and, ultimately, in economic growth'.

However, this 'weighing up' is not then done in any analytical fashion. Nor is there any real analysis behind the circular argument:

As long as New Zealand's commitment to fulfilling its obligations under the Kyoto Protocol was credible, it is unlikely that the country's international credibility would suffer if the domestic price of carbon were below the international price.

And it goes on:

Beyond CP1, if New Zealand had specific quantitative commitments, the issues would be the same. However, if New Zealand did not have such commitments, and did not intend to have such commitments in the foreseeable future, there would be no benefit from having the domestic price reflecting the international price.

This seems to suggest that New Zealand may opt out of taking on future commitments in the international regime that will come after 2012. In turn this indicates that some in government have not bought into the 
seriousness of climate change or the risk management strategy that underpinned the 2002 policy package.

\section{The way forward}

Officials have now been directed to report back to ministers in March 2006. Part of this will be on a work programme to develop a replacement set of policies. Also on the table is a restatement of the overarching objective(s) for climate change policy because it is now seen as 'unrealistic for New Zealand to achieve its internal target, namely gross emissions being set towards a permanent downward path by 2012'. One implication of this is that New Zealand might set a less challenging target at the very time the evidence is pointing to the need for urgent global action - and this is now being taken up daily in the world's media. What would this do to New Zealand's international credibility?

Given the significance of the issues at stake, what is needed is a robust and inclusive process that engages the country's best minds, from both within and outside government, with the objective of developing a coherent and durable climate change policy. Before officials and interested stakeholders begin to delve down into the details of possibly over-narrow tracks, this process should first step back and tackle the following set of high-level issues:

\section{Risk management}

Internationally, governmental initiatives to mitigate climate change are seen as increasingly urgent. Much more action needs to be taken globally in the next $10-20$ years to help prevent the crossing of 'tipping points ${ }^{34}$ that would lead to consequences described by many leading scientists and world thinkers as 'catastrophic'. What is New Zealand's strategic approach to managing such risks? How important is the credibility of our domestic action?

\section{Economic efficiency}

Unless New Zealand is contemplating backing away from any future international climate regime that generates an international carbon price, the principle that the international price of carbon should somehow guide efficient decision making in New Zealand must still hold. Or are we prepared to have the taxpayer foot the extra bill caused by inefficient decisions (for the lifetime of their effects) by just buying in overseas units?

4 Google 'tipping points and climate change' to get a good sense of the recent evidence on and media attention to this.
Economic instruments are widely regarded as being the means to get the carbon price signal to the correct point of decision making. Private agents (firms and individuals) know much better than government what their opportunities are to take cost-effective actions. But price-based (stick) policy tools should not be the only ones in the economic instrument toolkit that New Zealand will consider. For some sectors and actors in the economy, it needs to look also to other tools that can provide incentives at the international cost of carbon without imposing a cost of emissions. But how far is the use of 'carrots' acceptable?

\section{Implementing and sustaining policy}

In a policy area with the potential economic and social impacts of climate change, business and public support is critical for policy to be implemented and sustainable over time. This does not mean that policy cannot also be flexible and evolve over time as circumstances change (e.g. uncertainties become resolved). Two key issues are evident here:

- Do we expect that legitimate concerns about international competitiveness will continue for many of our major industries, and that domestic climate change policies should take heed of these concerns while they exist? In short, are (reviewable) exemption policies acceptable?

- Can revenue recycling be considered outside the trap of tax policy orthodoxy, so that price-based economic instruments can be used and garner popular support?

Murray Ward is the Principal of Global Climate Change Consultancy (GtripleC). He led the New Zealand Ministry for the Environment's climate change team from 1996 to the end of 2002, when New Zealand ratified the Kyoto Protocol and announced its domestic policy programme. He was a lead negotiator for New Zealand in the UNFCCC process and chaired key tasks in the development of the detailed Kyoto market mechanism rules. He also helped steer the development of domestic policy. 